\title{
Circulating Levels of Interleukin-1 Family Cytokines in Overweight Adolescents
}

\author{
Christian Jung, ${ }^{1,2}$ Norbert Gerdes, ${ }^{2,3}$ Michael Fritzenwanger, ${ }^{1}$ and Hans Reiner Figulla ${ }^{1}$ \\ ${ }^{1}$ Department of Internal Medicine I, Friedrich-Schiller-University, Erlanger Allee 101, 07747 Jena, Germany \\ ${ }^{2}$ Department of Medicine, Center for Molecular Medicine, Karolinska Institute, 17176 Stockholm, Sweden \\ ${ }^{3}$ Institute for Molecular Cardiovascular Research (IMCAR), RWTH Aachen University, 52074 Aachen, Germany
}

Correspondence should be addressed to Christian Jung, christian.jung@med.uni-jena.de

Received 4 October 2009; Accepted 17 November 2009

Academic Editor: Oreste Gualillo

Copyright () 2010 Christian Jung et al. This is an open access article distributed under the Creative Commons Attribution License, which permits unrestricted use, distribution, and reproduction in any medium, provided the original work is properly cited.

\begin{abstract}
Objectives. Obesity and related diseases are dramatically increasing problems, particularly in children and adolescents. We determined circulating levels of different interleukin (IL)-1 family members in normal weight and overweight adolescents. Methods. Seventy male, Caucasian adolescents (13-17 years) were recruited. Thirty-five had a body-mass index (BMI) above the 90th age-specific percentile. IL- $1 \alpha$, IL- $1 \beta$, IL-1 receptor antagonist (IL-1ra), and IL-18 were determined using multiplextechnology. Results. IL-18 concentrations were higher in the overweight group compared to normal weight $(161.6 \pm 40.7 \mathrm{pg} / \mathrm{ml}$ versus $134.7 \pm 43.4 \mathrm{pg} / \mathrm{ml}, P=.009)$. Concentrations of circulating IL- $1 \beta$ levels were below the detection threshold. IL-18 $\left(R^{2}: 0.355\right.$, $P<.01)$ and IL-1ra $\left(R^{2}: 0.287, P<.05\right)$ correlated with BMI, whereas IL- $1 \alpha$ did not. Conclusions. Accumulating data indicate the importance of the endocrine function of adipose tissue for the pathophysiological consequences of obesity-related co-morbidities. Since IL-18 is involved in the pathogenesis of different cardiovascular diseases, we conclude that IL-18 may represent a link between obesity and related co-morbidities in children and adolescents.
\end{abstract}

\section{Introduction}

Overweight and the related metabolic syndrome are dramatically increasing problems, particularly in children and adolescents $[1,2]$.

Being overweight in early life significantly increases the risk for and severity of obesity in adulthood [3]. Obesity increases the risk for related morbidities such as the metabolic syndrome (MS), which is defined as a clustering of cardiovascular risk factors, including impaired glucose tolerance, dyslipidemia, and hypertension. Obesity, especially abdominal obesity, is a hallmark of the MS and insulin resistance, a consequence of abdominal obesity. In addition, abdominal obesity is considered to be the driving force of the MS. Furthermore, type 2 diabetes mellitus (T2D) now accounts for up to 45 percent of all newly diagnosed diabetes in pediatric patients in northern America [4].

In the last decade, increasing evidence suggested the striking relevance of a low but chronic inflammatory state in obesity and MS. Population-based studies have shown strong relationship between inflammatory markers and lipid metabolism abnormalities, obesity, and resulting complications such as atherosclerosis $[5,6]$. This presence of chronic low-grade inflammation in obese states, in insulin resistance, the MS, and T2D, and in early stages of atherogenesis supports the notion that inflammation may be the causal link connecting adipose tissue dysfunction with metabolic and vascular pathologies [7]. Research of recent years revealed a role of adipose tissue beyond energy storage harboring inflammatory cells which are believed to sustain inflammation and impair adipocyte function [8]. These effects might be mediated by cytokines released in substantial amounts from adipocytes, as well as from inflammatory cells recruited into adipose tissue. Many proinflammatory cytokines such as tumor necrosis factor alpha $(\mathrm{TNF} \alpha)$ and interleukin (IL)-6, as well as other markers like leptin, adiponectin, and stromal-derived-factor (SDF) 1 in overweight children and adolescents have attracted considerable attention [913]. In addition, cytokines of the IL-1 family have been described to be elevated in overweight adults. This family 
includes among others IL- $1 \alpha$, IL-1 receptor antagonist (IL$1 \mathrm{ra})$, IL-1 $\beta$, and IL-18. Both proinflammatory cytokines, IL-1 $\beta$ and IL18, are elevated in adult obesity and share a similar signal transduction pathway [14]. The IL-1ra is an anti-inflammatory cytokine that is also produced by white adipose tissue. IL-1ra binds to the IL-1 receptor in a nonactivating fashion competing with and antagonizing the proinflammatory IL-1 [15]. Systemic levels of IL-1ra were shown to be elevated in obese adults likely representing a protective response to the rise of IL-1 [16].

The aim of this study was to investigate circulating levels of IL-1 family cytokines in adolescents and the influence of obesity in early life as well as the correlation to markers of glucose metabolism (adiponectin) and endothelial damage.

\section{Methods}

2.1. Study Subjects. Voluntary individuals were recruited in schools of the region of Jena, Germany. Seventy male, Caucasian adolescents (aged 13-17 years) were studied. Of these $35(50 \%)$ had a body-mass index (BMI) above the 90th percentile according to German charts [17]. Subjects and their parents gave informed consent and protocols were approved by the University's ethics committee in accordance with the Helsinki Declaration II.

For all participants the following parameters were recorded in one consultation: age, height, weight, waist and hip circumference, heart rate, and blood pressure (systolic and diastolic). Any sign of disease was an exclusion criterion. BMI was calculated with the formula: body weight $[\mathrm{kg}] /$ height $[\mathrm{cm}]^{2}$. BMI-standard deviation score (SDS) was calculated according to current guidelines using German charts [17]. Briefly, the formula BMI-SDS= $\left([\mathrm{BMI} / \mathrm{M}(\mathrm{t})]^{\mathrm{L}(\mathrm{t})}-1\right) / \mathrm{L}(\mathrm{t}) * \mathrm{~S}(\mathrm{t})$ was used. $\mathrm{M}(\mathrm{t})$ is the age- and sex-specific BMI median. $\mathrm{L}(\mathrm{t})$ and $\mathrm{S}(\mathrm{t})$ are age and sexspecific calculation variables available in charts.

2.2. Routine Laboratory. Blood samples were drawn in the morning after an overnight fast using EDTA as anticoagulant. Standard plasma parameters were obtained from the Department of Clinical Chemistry at the University Hospital Jena: high-density lipoprotein (HDL; mmol/l), low-density lipoprotein (LDL; $\mathrm{mmol} / \mathrm{l})$, triglycerides $(\mathrm{mmol} / \mathrm{l})$, and Creactive protein (CRP, $\mathrm{mg} / \mathrm{l}$; using high sensitivity assay) were analyzed.

2.3. Cytokine Determination. The quantitative determination of human IL- $1 \alpha$, IL- $1 \beta$, IL-1ra, and IL- 18 was performed using immediately frozen plasma $\left(-70^{\circ} \mathrm{C}\right)$. Cytokines were determined by Bio-Plex technology according to the manufacturer's instructions (Bio-Rad, Hercules, CA). Briefly, fluorescently-dyed microspheres coated with a capture antibody bind to relevant cytokines in a sandwich immunoassay format. Following removal of unbound sample specific protein was detected with a fluorescently labeled antibody and analyzed in a Luminex analyzer [18].
2.4. ELISA. As surrogate markers for insulin sensitivity and glucose metabolism [19] and for early endothelial damage $[20]$ and activation, adiponectin and soluble E-selectin (sEselectin),respectively, were measured using ELISA technique according to manufacturer's instructions (R\&D Systems, Wiesbaden, Germany).

2.5. Statistical Analysis. Cytokine levels between groups were compared with $t$-test. Correlation analyses between cytokine levels and other laboratory values or patient characteristics employed Pearson correlation coefficient. For correlation between cytokines and the ELISA markers, linear regression analysis was also used. Statistical significance was assumed if a null hypothesis could be rejected at $P \leq .05$. All statistical analyses were performed with SPSS, version 12.0 (SPSS Inc.).

\section{Results}

The baseline characteristics are shown in Table 1. Overweight adolescents had higher BMI, BMI-SDS, waist circumference, and systolic blood pressure at rest. Levels of triglycerides, total cholesterol, and LDL did not differ, but HDL was lower in overweight adolescents. In addition, overweight adolescents had higher levels of CRP likely reflecting a lowgrade inflammatory state.

Concentrations of circulating IL- $1 \beta$ levels were below the detection threshold. IL- $1 \alpha$ (normal weight: $29.40 \pm 7.81 \mathrm{pg} / \mathrm{mL}$ versus overweight: $31.62 \pm 9.26 \mathrm{pg} / \mathrm{mL}$; $P=.281$ ) and IL-1ra (normal weight: $203.79 \pm 178.18 \mathrm{pg} / \mathrm{mL}$ versus overweight: $280.15 \pm 213.37 \mathrm{pg} / \mathrm{mL} ; P=.109$ ) levels did not differ significantly, whereas IL-18 was higher in overweight adolescents $(134.73 \pm 43.38 \mathrm{pg} / \mathrm{mL}$ versus $161.57 \pm 40.67 \mathrm{pg} / \mathrm{mL} ; P=.009)$.

IL-1ra and IL-18 correlated with all anthropometrical measurements of obesity, including body weight, BMI, BMI-SDS, and waist circumference, whereas IL- $1 \alpha$ did not (Table 2). Blood pressure levels at rest had no association with any of the investigated cytokines. Triglycerides, total cholesterol, and LDL cholesterol correlated with IL$1 \alpha$, whereas HDL cholesterol correlated inversely with IL18. Higher inflammatory state determined by CRP was associated with higher IL- $1 \alpha$ and IL-18. To further dissect the relevance of IL-1 family cytokines, we correlated (linear regression analysis) these markers with adiponectin as surrogate for beginning insulin resistance and glucose metabolism and sE-selectin as plasma correlate for functional and morphological changes in the vessel wall in teenagers. IL- $1 \alpha$, IL-18, and IL-1ra did not correlate with adiponectin (data not shown). Correlation of sE-selectin to IL-1ra also did not show significant results, but sE-selectin correlated to IL- $1 \alpha$ and IL-18 (both $P<.001$, Figure 1).

\section{Discussion}

During the past decades, the industrialized countries witnessed a dramatic increase in the prevalence of obesity. Recent research has clearly confirmed that overweight and especially obesity are associated with a chronic subclinical 
TABLE 1: Characteristics of the study population. Data are presented as mean \pm standard deviation. n.s.: not significant.

\begin{tabular}{|c|c|c|c|}
\hline & Normal weight adolescents & Overweight adolescents & $P$-value \\
\hline $\mathrm{N}$ & 35 & 35 & \\
\hline Age (Years) & 15.3 & 15.1 & n.s. \\
\hline Body Weight (kg) & $63.3 \pm 7.6$ & $97.0 \pm 19.3$ & $<.001$ \\
\hline BMI & $20.5 \pm 1.9$ & $32.1 \pm 5.2$ & $<.001$ \\
\hline BMI-SDS & $0.05 \pm 0.68$ & $2.39 \pm 0.52$ & $<.001$ \\
\hline Waist circumference $(\mathrm{cm})$ & $72.7 \pm 4.4$ & $100.2 \pm 13.5$ & $<.001$ \\
\hline Systolic blood pressure $(\mathrm{mmHg})$ & $120 \pm 11$ & $134 \pm 17$ & .021 \\
\hline Triglycerides (mmol/l) & $0.89 \pm 0.29$ & $1.12 \pm 0.74$ & n.s. \\
\hline Total cholesterol (mmol/l) & $3.92 \pm 0.79$ & $4.09 \pm 0.77$ & n.s. \\
\hline LDL cholesterol $(\mathrm{mmol} / \mathrm{l})$ & $2.37 \pm 0.82$ & $2.55 \pm 0.72$ & n.s. \\
\hline HDL cholesterol (mmol/l) & $1.27 \pm 0.21$ & $1.10 \pm 0.22$ & .002 \\
\hline High-sensitive CRP (mg/dl) & $0.52 \pm 1.49$ & $2.69 \pm 3.19$ & .001 \\
\hline
\end{tabular}

TABLE 2: Correlation of IL-1 $\boldsymbol{\alpha}$, IL-1ra, and IL-18 to anthropometrical measurements of obesity, patient characteristics, and different lab values. Indicated is the Pearson correlation coefficient $\left(R^{2}\right)$.

\begin{tabular}{lccc}
\hline & IL- $1 \alpha$ & IL-1ra & IL-18 \\
\hline Body Weight & $0.217^{\mathrm{ns}}$ & $0.366^{* *}$ & $0.346^{* *}$ \\
BMI & $0.200^{\mathrm{ns}}$ & $0.287^{*}$ & $0.355^{* *}$ \\
BMI-SDS & $0.198^{\mathrm{ns}}$ & $0.284^{*}$ & $0.349^{* *}$ \\
Waist circumference & $0.221^{\mathrm{ns}}$ & $0.346^{* *}$ & $0.366^{* *}$ \\
Systolic blood pressure & $-0.110^{\mathrm{ns}}$ & $-0.065^{\mathrm{ns}}$ & $-0.302^{\mathrm{ns}}$ \\
Triglycerides & $0.331^{* *}$ & $0.242^{* *}$ & $0.225^{\mathrm{ns}}$ \\
Total cholesterol & $0.332^{* *}$ & 0.166 & 0.055 \\
LDL cholesterol & $0.333^{* *}$ & $0.120^{\mathrm{ns}}$ & $0.202^{\mathrm{ns}}$ \\
HDL cholesterol & $-0.152^{\mathrm{ns}}$ & $-0.194^{\mathrm{ns}}$ & $-0.239^{*}$ \\
CRP & $0.298^{*}$ & $0.208^{\mathrm{ns}}$ & $0.277^{*}$ \\
\hline
\end{tabular}

ns:not significant

*:significant at 0.05 level

$* *$ :significant at 0.01 level

inflammation [21]. Adipose tissue is not merely a simple reservoir of energy stored as triglycerides, but serves as an active secretory organ releasing many peptides and cytokines into the circulation. In the state of obesity, the balance between these numerous molecules is dysregulated. Enlargement of adipocytes producing more proinflammatory cytokines (i.e. TNF $\alpha$, IL-6) and less anti-inflammatory proteins, such as adiponectin, was suggested as one potential explanation [22]. Others proposed that infiltration of inflammatory cells may represent the critical step in adipose tissueassociated inflammation, although the initial trigger(s) for accumulation of these cells remains elusive. The present study extends the existing knowledge about alterations in the IL-1 family in obese adults to obese teenagers.

Elevation of IL- $1 \alpha$ and IL-1ra has been described under different conditions, including overweight and diabetes, while circulating levels of IL-1 $\beta$ were reported below the sensitivity of the assays $[23,24]$. Of note, the pathophysiological link between obesity and resulting T2D mediated by IL- $1 \alpha$, IL- $1 \beta$, and their antagonist IL-1ra is discussed in current literature, but is not completely understood. While
IL- $1 \alpha$ inhibits insulin signaling in adipocytes [25], IL- $1 \beta$ mediated cytotoxic effects in pancreatic islets consequently leading to impaired insulin secretion [26]. Therefore, IL-1ra received considerable clinical attention due to the potential therapeutic application of this natural inhibitor. Interestingly, treatment with an IL-1 antibody improves glycemic control in diet-induced obesity in mice [27]. In adolescents these cytokines-if detectable-did not differ significantly between groups. However, mean numbers in overweight adolescents showed a trend for IL-1ra to be increased and IL-1ra correlated with anthropometrical measurements of obesity, such as waist circumference, which is a good marker for visceral adipose tissue. This correlation suggests that the recruitment of this endogenous protective mechanism already starts in early life controlling activation of the IL1 axis. Furthermore, we observed an intriguing association between IL- $1 \alpha$ and sE-selectin. Invitro studies showed that IL- $1 \alpha$ promotes procoagulative activity and inflammation in endothelial cells [28]. Since circulating levels of sE-selectin reflect remarkably well structural and functional changes of the vessel wall in early life [20], it is tempting to speculate 


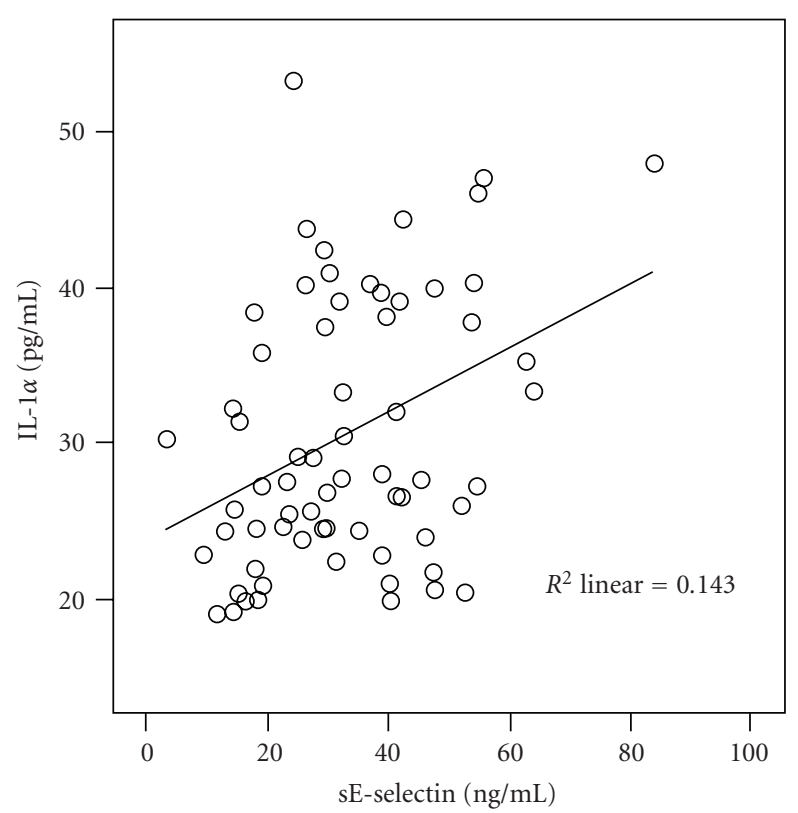

(a)

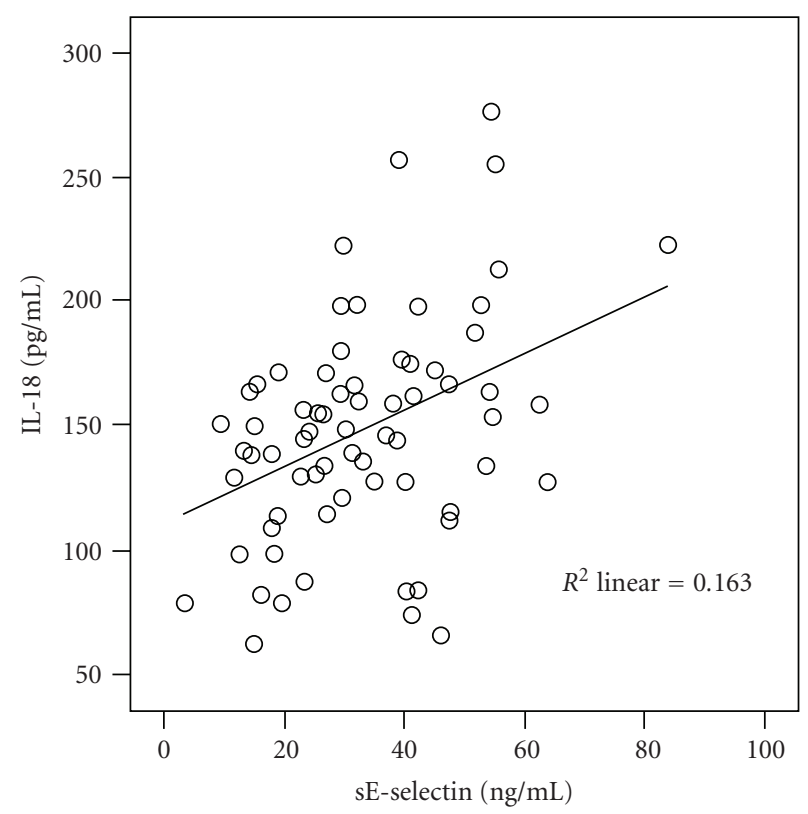

(b)

FIgure 1: Association of soluble E-selectin (sE-selectin) with IL- $1 \alpha$ (a) and IL-18 (b). Both correlations: $P<.001$.

whether IL- $1 \alpha$ is involved into such changes. Future studies will have to elucidate this question.

IL-18 is closely related to IL- $1 \beta$ sharing structural and functional similarities. Both the IL-1 receptor and IL-18 receptor belong to the same receptor superfamily [29]. IL-18 is implicated in the pathogenesis of several diseases including atherosclerosis and ischemic heart disease [30-32], and more recently a novel function for IL-18 in the control of energy homeostasis has also been described [33]. Zirlik et al. and others reported that circulating levels of IL-18 in human adults directly correlate with BMI, adiposity, and insulin resistance and are elevated in obesity [31,34]. In adipose tissue, resident macrophages are the major source of IL-18 [35], supported by Fain et al., showing that the nonfat cells in human adipose tissue contribute to most of the release of IL-18 [36]. These results highlight the importance of IL-18 in obesity, furthermore, supported by animal studies showing that IL-18 modulates food-intake, leading to hyperphagia in IL-18 deficient mice [37]. In our adolescent cohort, IL-18 is elevated in overweight individuals and correlates with different anthropometrical measurements of obesity. Furthermore, it is associated with inflammatory state (CRP) and endothelial damage (sE-selectin), underlining the early development of atherosclerosis in overweight teenagers and the connecting role of inflammation mediated by factors such as IL-18. Since insulin resistance is a crucial component of MS, it is surprising that IL-18 is not associated (inverse) with adiponectin. However, our data corroborate previous studies reporting that in obese children and adults, IL-18 levels can be independent of the alterations in adiponectin $[38,39]$.

Zilverschoon et al. recently proposed a mechanism of IL-18 resistance which is of potential relevance for the understanding of the consequences of high IL-18 levels [40]. In their study obese adults are characterized by higher levels of IL-18, but their leucocytes show lower response to IL18 stimulation. The development of IL-18 resistance may provide an explanation for the increased susceptibility of overweight subjects for infections. This hypothesis, which remains to be tested, may also hold true for children and adolescents since an increased frequency of infections was reported for obese or overweight subjects [41]. Thus, future studies have to address the correlations between IL-18 levels, obesity, and infections in early life.

We would like to discuss some strengths and weaknesses of our study: a limitation is that the study cohort is comparably small. Since IL-1ra correlated well with different anthropometrical measurements of obesity, it is reasonable to speculate that there might also be a difference between groups if group size would be bigger. However, group sizes were powerful enough to reveal striking differences for a related cytokine of the same family. An obvious strength of this study is that it—-to the best of our knowledge-for the first time investigates IL-1 family cytokines in normal weight and overweight adolescents.

In summary, we conclude that cytokines of IL-1 family are involved in pathophysiological conditions that occur in overweight adolescents. Notably, IL-18 is elevated in overweight teenagers, correlating with different anthropometrical measurement of obesity and associated with sE-selectin, a marker for endothelial damage. However, IL- $1 \alpha$ and IL-1ra are not significantly elevated and may not contribute to the pathophysiology that increases the frequency of diabetes in overweight adolescents. Early changes in cytokine profile underline the urgency of fighting obesity in childhood and adolescence. 


\section{Acknowledgments}

The authors thank Annett Schmidt (Jena), Dr. Peter Iversen, and Dr. Eva Fernvik (Biorad) for excellent technical assistance. Christian Jung is supported by IZKF Jena and Norbert Gerdes by the Leducq Network on Atherothrombosis and the Swedish Research Council.

\section{References}

[1] C. L. Ogden, M. D. Carroll, L. R. Curtin, M. A. McDowell, C. J. Tabak, and K. M. Flegal, "Prevalence of overweight and obesity in the United States, 1999-2004," Journal of the American Medical Association, vol. 295, no. 13, pp. 1549-1555, 2006.

[2] G. Wang and W. H. Dietz, "Economic burden of obesity in youths aged 6 to 17 years: 1979-1999," Pediatrics, vol. 109, no. 5, article e81, 2002.

[3] W. H. Dietz and T. N. Robinson, "Overweight children and adolescents," The New England Journal of Medicine, vol. 352, no. 20, pp. 2100-2109, 2005.

[4] A. Fagot-Campagna, D. J. Pettitt, M. M. Engelgau, et al., "Type 2 diabetes among North American children and adolescents: an epidemiologic review and a public health perspective," Journal of Pediatrics, vol. 136, no. 5, pp. 664-672, 2000.

[5] P. Dandona, A. Aljada, and A. Bandyopadhyay, "Inflammation: the link between insulin resistance, obesity and diabetes," Trends in Immunology, vol. 25, no. 1, pp. 4-7, 2004.

[6] C. Jung, N. Fischer, M. Fritzenwanger, and H. R. Figulla, "Anthropometric indices as predictors of the metabolic syndrome and its components in adolescents," to appear in Pediatrics International.

[7] K. Alexandraki, C. Piperi, C. Kalofoutis, J. Singh, A. Alaveras, and A. Kalofoutis, "Inflammatory process in type 2 diabetes: the role of cytokines," Annals of the New York Academy of Sciences, vol. 1084, pp. 89-117, 2006.

[8] H. Xu, G. T. Barnes, Q. Yang, et al., "Chronic inflammation in fat plays a crucial role in the development of obesity-related insulin resistance," Journal of Clinical Investigation, vol. 112, no. 12, pp. 1821-1830, 2003.

[9] G. Fantuzzi, "Adipose tissue, adipokines, and inflammation," Journal of Allergy and Clinical Immunology, vol. 115, no. 5, pp. 911-920, 2005.

[10] C. Jung, N. Fischer, M. Fritzenwanger, J. Pernow, B. R. Brehm, and H. R. Figulla, "Association of waist circumference, traditional cardiovascular risk factors, and stromal-derived factor-1 in adolescents," Pediatric Diabetes, vol. 10, no. 5, pp. 329-335, 2009.

[11] C. Jung, M. Fritzenwanger, N. Fischer, and H. R. Figulla, "Hepatocyte growth factor is elevated in obese adolescents," Journal of Pediatric Endocrinology and Metabolism, vol. 22, no. 7, pp. 645-651, 2009.

[12] J. Y. Shin, S. Y. Kim, M. J. Jeung, et al., "Serum adiponectin, Creactive protein and TNF- $\alpha$ levels in obese Korean children," Journal of Pediatric Endocrinology and Metabolism, vol. 21, no. 1, pp. 23-29, 2008.

[13] C. Jung, M. Fritzenwanger, and H. R. Figulla, "Cardiotrophin1 in adolescents: impact of obesity and blood pressure," Hypertension, vol. 52, no. 2, article e6, 2008.

[14] O. Osborn, H. Gram, E. P. Zorrilla, B. Conti, and T. Bartfai, "Insights into the roles of the inflammatory mediators IL1, IL-18 and PGE2 in obesity and insulin resistance," Swiss Medical Weekly, vol. 138, no. 45-46, pp. 665-673, 2008.
[15] C. E. Juge-Aubry, E. Somm, V. Giusti, et al., "Adipose tissue is a major source of interleukin-1 receptor antagonist: upregulation in obesity and inflammation," Diabetes, vol. 52, no. 5, pp. 1104-1110, 2003.

[16] C. A. Meier, E. Bobbioni, C. Gabay, F. AssimacopoulosJeannet, A. Golay, and J.-M. Dayer, "IL-1 receptor antagonist serum levels are increased in human obesity: a possible link to the resistance to leptin?" Journal of Clinical Endocrinology and Metabolism, vol. 87, no. 3, pp. 1184-1188, 2002.

[17] K. Kromeyer-Hauschild, M. Wabitsch, D. Kunze, et al., "Perzentile für den body-mass-index für das kindes- und jugendalter unter heranziehung verschiedener deutscher stichproben," Monatsschrift für Kinderheilkunde, vol. 149, no. 8, pp. 807-818, 2001.

[18] I. H. Khan, V. V. Krishnan, M. Ziman, et al., "A comparison of multiplex suspension array large-panel kits for profiling cytokines and chemokines in rheumatoid arthritis patients," Cytometry B, vol. 76, no. 3, pp. 159-168, 2009.

[19] C. Herder, S. Schneitler, W. Rathmann, et al., "Low-grade inflammation, obesity, and insulin resistance in adolescents," Journal of Clinical Endocrinology and Metabolism, vol. 92, no. 12, pp. 4569-4574, 2007.

[20] A. A. Meyer, G. Kundt, M. Steiner, P. Schuff-Werner, and W. Kienast, "Impaired flow-mediated vasodilation, carotid artery intima-media thickening, and elevated endothelial plasma markers in obese children: the impact of cardiovascular risk factors," Pediatrics, vol. 117, no. 5, pp. 1560-1567, 2006.

[21] S. P. Weisberg, D. McCann, M. Desai, M. Rosenbaum, R. L. Leibel, and A. W. Ferrante Jr., "Obesity is associated with macrophage accumulation in adipose tissue," Journal of Clinical Investigation, vol. 112, no. 12, pp. 1796-1808, 2003.

[22] R. Weiss and S. Caprio, "The metabolic consequences of childhood obesity," Best Practice and Research: Clinical Endocrinology and Metabolism, vol. 19, no. 3, pp. 405-419, 2005.

[23] S. Perrier, F. Darakhshan, and E. Hajduch, "IL-1 receptor antagonist in metabolic diseases: Dr Jekyll or Mr Hyde?" FEBS Letters, vol. 580, no. 27, pp. 6289-6294, 2006.

[24] J. S. Rosa, R. L. Flores, S. R. Oliver, A. M. Pontello, F. P. Zaldivar, and P. R. Galassetti, "Sustained IL- $1 \alpha$, IL-4, and IL6 elevations following correction of hyperglycemia in children with type 1 diabetes mellitus," Pediatric Diabetes, vol. 9, no. 1, pp. 9-16, 2008.

[25] J. He, I. Usui, K. Ishizuka, et al., "Interleukin-1 $\alpha$ inhibits insulin signaling with phosphorylating insulin receptor substrate-1 on serine residues in 3T3-L1 adipocytes," Molecular Endocrinology, vol. 20, no. 1, pp. 114-124, 2006.

[26] K. Maedler, P. Sergeev, F. Ris, et al., "Glucose-induced $\beta$ cell production of IL- $1 \beta$ contributes to glucotoxicity in human pancreatic islets," Journal of Clinical Investigation, vol. 110, no. 6, pp. 851-860, 2002.

[27] O. Osborn, S. E. Brownell, M. Sanchez-Alavez, D. Salomon, H. Gram, and T. Bartfai, "Treatment with an Interleukin 1 beta antibody improves glycemic control in diet-induced obesity," Cytokine, vol. 44, no. 1, pp. 141-148, 2008.

[28] G. J. Brunn, S. Saadi, and J. L. Platt, "Differential regulation of endothelial cell activation by complement and interleukin $1 \alpha$," Circulation Research, vol. 98, no. 6, pp. 793-800, 2006.

[29] D. Boraschi and A. Tagliabue, "The interleukin-1 receptor family," Vitamins and Hormones, vol. 74, pp. 229-254, 2006.

[30] Z. Mallat, A. Corbaz, A. Scoazec, et al., "Expression of interleukin-18 in human atherosclerotic plaques and relation to plaque instability," Circulation, vol. 104, no. 14, pp. 15981603, 2001. 
[31] A. Zirlik, S. M. Abdullah, N. Gerdes, et al., "Interleukin-18, the metabolic syndrome, and subclinical atherosclerosis: results from the Dallas Heart Study," Arteriosclerosis, Thrombosis, and Vascular Biology, vol. 27, no. 9, pp. 2043-2049, 2007.

[32] N. Gerdes, G. K. Sukhova, P. Libby, R. S. Reynolds, J. L. Young, and U. Schönbeck, "Expression of interleukin (IL)-18 and functional IL-18 receptor on human vascular endothelial cells, smooth muscle cells, and macrophages: implications for atherogenesis," Journal of Experimental Medicine, vol. 195, no. 2, pp. 245-257, 2002.

[33] E. P. Zorrilla, M. Sanchez-Alavez, S. Sugama, et al., "Interleukin-18 controls energy homeostasis by suppressing appetite and feed efficiency," Proceedings of the National Academy of Sciences of the United States of America, vol. 104, no. 26, pp. 11097-11102, 2007.

[34] K. Esposito, A. Pontillo, M. Ciotola, et al., "Weight loss reduces interleukin-18 levels in obese women," Journal of Clinical Endocrinology and Metabolism, vol. 87, no. 8, pp. 3864-3866, 2002.

[35] T. Skurk, H. Kolb, S. Müller-Scholze, K. Röhrig, H. Hauner, and C. Herder, "The proatherogenic cytokine interleukin18 is secreted by human adipocytes," European Journal of Endocrinology, vol. 152, no. 6, pp. 863-868, 2005.

[36] J. N. Fain, D. S. Tichansky, and A. K. Madan, "Most of the interleukin 1 receptor antagonist, cathepsin S, macrophage migration inhibitory factor, nerve growth factor, and interleukin 18 release by explants of human adipose tissue is by the non-fat cells, not by the adipocytes," Metabolism: Clinical and Experimental, vol. 55, no. 8, pp. 1113-1121, 2006.

[37] M. G. Netea, L. A. B. Joosten, E. Lewis, et al., "Deficiency of interleukin-18 in mice leads to hyperphagia, obesity and insulin resistance," Nature Medicine, vol. 12, no. 6, pp. 650 656, 2006.

[38] J. Hung, B. M. McQuillan, P. L. Thompson, and J. P. Beilby, "Circulating adiponectin levels associate with inflammatory markers, insulin resistance and metabolic syndrome independent of obesity," International Journal of Obesity, vol. 32, no. 5, pp. 772-779, 2008.

[39] L. Gilardini, P. G. McTernan, A. Girola, et al., "Adiponectin is a candidate marker of metabolic syndrome in obese children and adolescents," Atherosclerosis, vol. 189, no. 2, pp. 401-407, 2006.

[40] G. R. C. Zilverschoon, C. J. Tack, L. A. B. Joosten, B. J. Kullberg, J. W. M. van der Meer, and M. G. Netea, "Interleukin18 resistance in patients with obesity and type 2 diabetes mellitus," International Journal of Obesity, vol. 32, no. 9, pp. 1407-1414, 2008.

[41] E. Erdem, B. A. Kogan, and P. J. Feustel, "Relationship between body mass index and pediatric urologic diagnoses," Journal of Pediatric Urology, vol. 3, no. 4, pp. 268-272, 2007. 


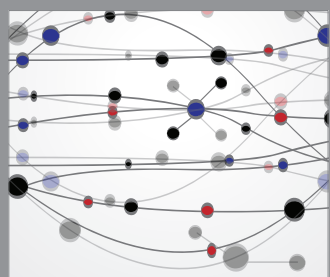

The Scientific World Journal
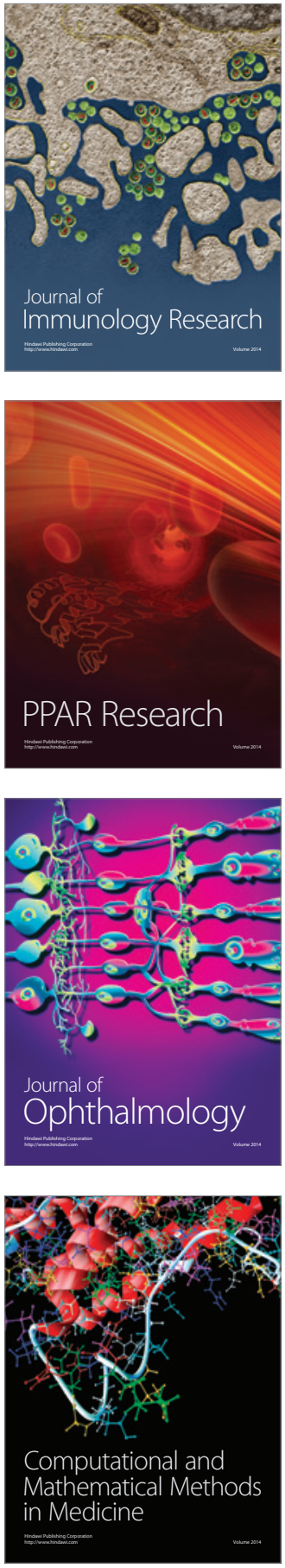

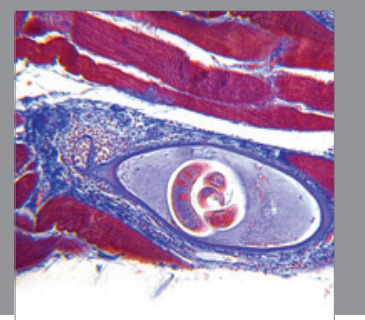

Gastroenterology

Research and Practice
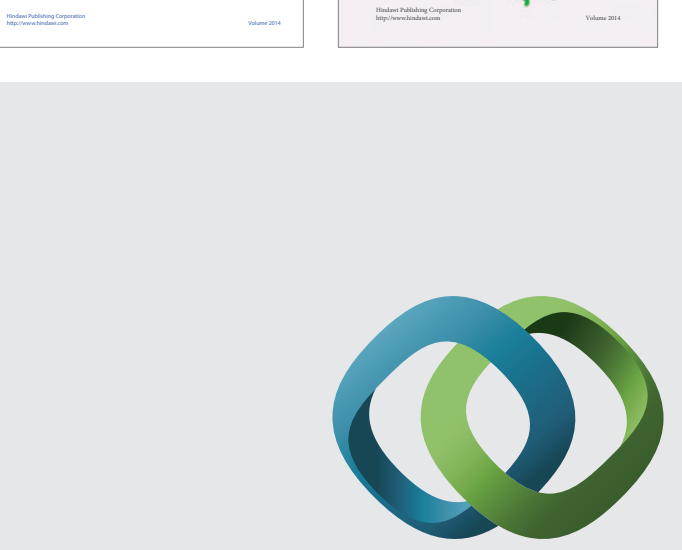

\section{Hindawi}

Submit your manuscripts at

http://www.hindawi.com
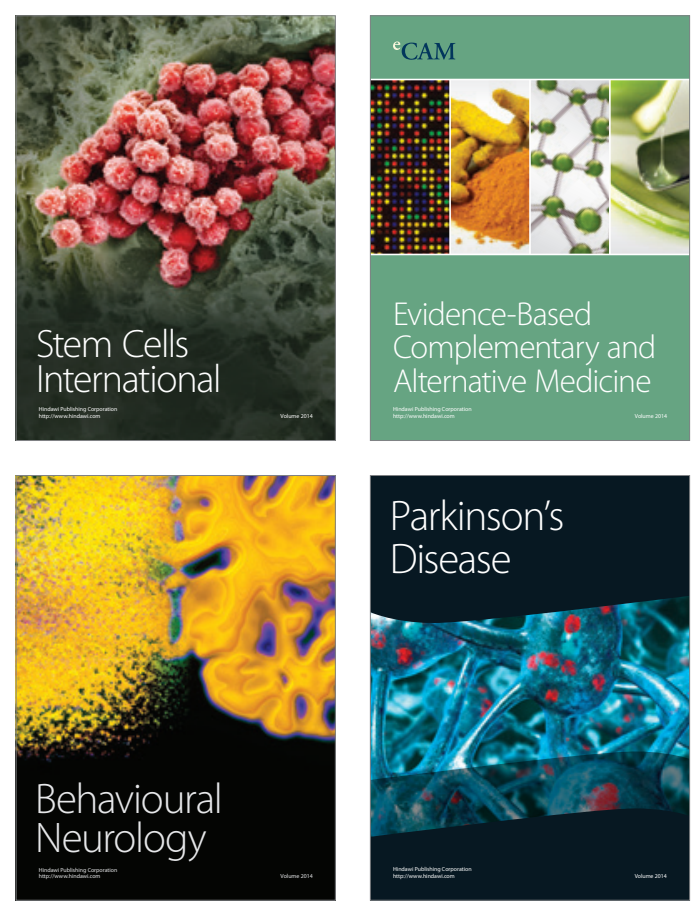

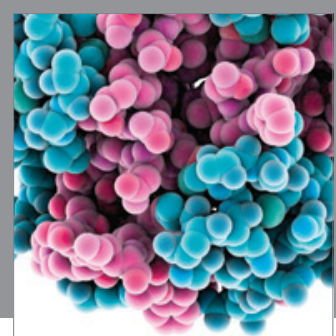

Journal of
Diabetes Research

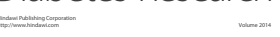

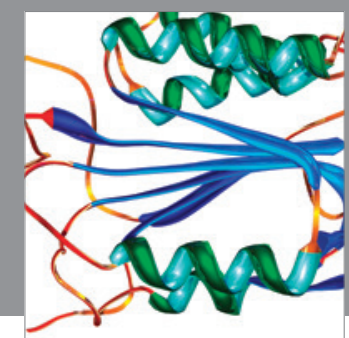

Disease Markers
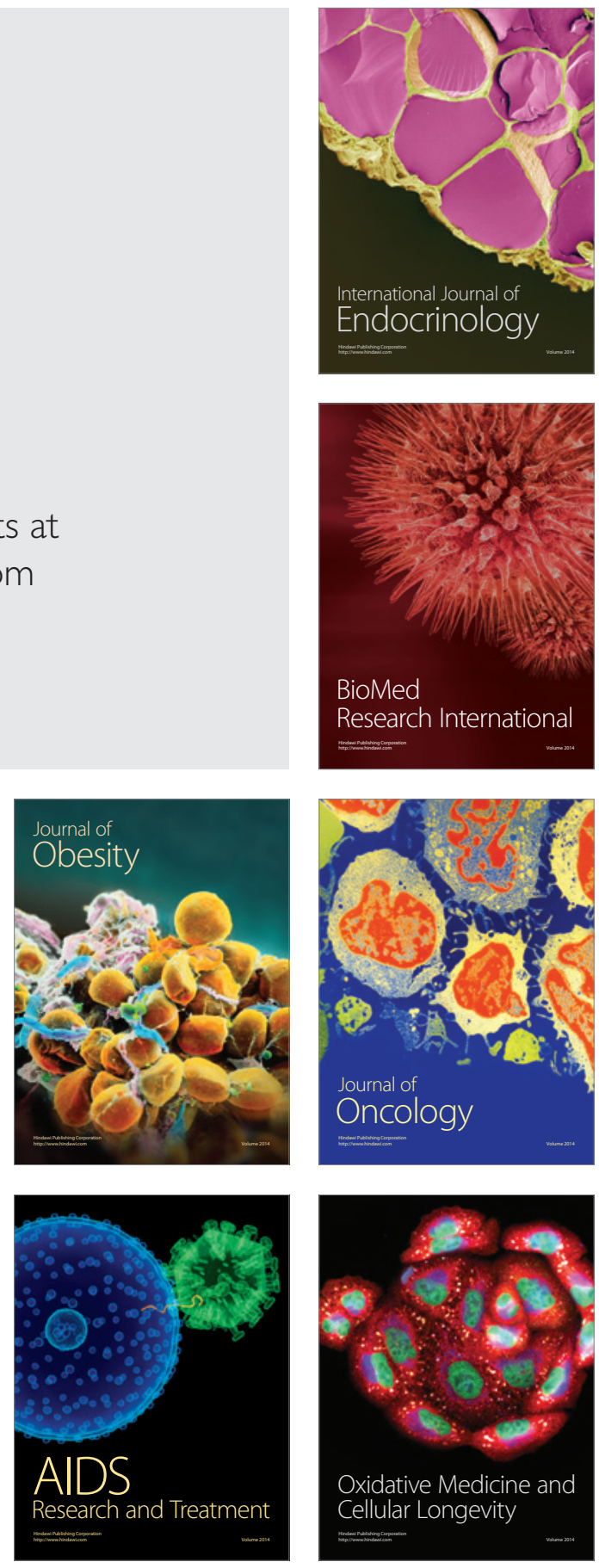